descriptions. that the effect of the instructions to "describe the stimulus so that you could later reproduce it from your description" was to produce unduly verbose descriptions to assure retrievability.

Glanzer \& Cunitz (1966) provide another possible reason for the failure of the verbal loop hypothesis to predict S's ability on the experimental task. In at tempting to account for the serial-position effect in free recall of a list, they assume the operation of a short-term and a long-term memory system. It may well be that in the present experiment both short-term visual and long-term auditory memory are being utilized and the effect of the former may confound the action of the latter.

The findings reported herein are in agreement with the results reported by Sang \& Ross (1970) and suggest that the verbal loop liypothesis may require modification and further testing.

\title{
Recognition reaction time and size of the memory set: A developmental study*
}

\section{KENNETH L. HOVING, ROBERT E. MORIN, and DOROTHY S. KONICK Kent State University, Kent, Ohio 44240}

Kindergarten, fourth-grade, and college Ss were tested on a recognition reaction-time task with memory sets of two, three, and four items. Though overall reaction time (RT) varied with age, the slopes of the functions relating RT to size of the memory set did not differ significantly as a function of age. Within the context of a theory of recognition memory developed by Sternberg (1966), the results suggest that young children scan memory for familiar pictures as quickly as do adults.

Sternberg (1967) has identified two processes which underlie the recognition of a stimulus as a member of a previously learned set. One is the formation of a representation of the test stimulus. The second is a memory search or comparison process in which the encoded test stimulus is compared serially and exhaustively to items represented in memory. The search is serial in that comparisons occur one at a time, and it is exhaustive in that the encoded test stimulus is checked against evt,y item in the memorized set.

The temporal parameter of the search process is the slope of a linear function which relates reaction time (RT) of the recognition response to size of the memory set (Sternberg, 1963, 1966). The slope describes the rate at which memory is searched, i.e., the time required for each

*This study was supported by the United States Public Health Service, National Institute of Child Health and Human Development. Grant No. HD-02086. The cooperation of Walls Flementary School and Kent State Liniversity School of Kent. Ohio, is gratefully acknowledged. comparison. The intercept of the function is a composite measure of the times taken by other processes which precede and follow the search, including the time for stimulus encoding. Indeed, Sternberg (1967) has demonstrated that when $S$ is shown a visually degraded test stimulus, additional time is required prior to memory search for transforming the stimulus into a usable representation. After a session of practice, degrading the test stimulus was found to increase the intercept of the RT-set size function but not to change its slope.

Sternberg's theory and procedures are potentially useful for understanding differences between the RTs of children and adults. Why do children react more slowly? The longer RTs may reflect slower memory search, slower perceptual and motor processes, or a combination of effects. The present investigation examines RT as a function of set size for children and adults.

\section{SUBJECTS}

There were $54 \mathrm{Ss}$, nine males and nine females from kindergarten, fourth-grade, and college classes. Only students of ages appropriate to their grade leveis were tested.

\section{STIMULI AND TRIALS}

The stimuli were line drawings of 27 highly familiar objects (e.g., hammer, dog, shirt) and were divided randomly into three groups of nine. Each stimulus group was further subdivided into sets of two, three, and four elements such that any subset could be designated as the positive memory set, with remaining elements negative. Nine additional drawings were used in pretraining and practice. Slides of each picture were prepared for presentation as test stimuli. Projected slides appeared as $4 \times 6$ in. white-on-black line drawings. The stimulus pictures were also printed on $5 \times 8$ in. cards, which were used to teach $S s$ the membership of memory sets.

Two experimental sessions were each divided into three blocks of trials. Prior to a block of trials, $S$ was shown a memory set of two, three, or four stimuli. A trial block consisted of sequentially presented test stimuli. The $S$ 's task was to respond positively to a test stimulus if it was in the memory set and negatively if it was not. There were 4 warm-up and 18 test trials in a block: one-third of the test trials were positive and two-thirds were negative. For a given $S$ the three trial blocks in a session were each associated with a different group of nine stimuli and a different size of memory set. The order of testing each set size and the group of stimuli associated with each set size were counterbalanced across Ss for Day 1. On Day 2 each $S$ received the same trial blocks as on Day 1 , but in reverse order.

\section{APPARATUS}

Slides were rear-projected on a milk-glass screen located $2 \mathrm{ft}$ from $\mathrm{S}$ at eye level. An auditory signal provided a $1-\mathrm{sec}$ warning in advance of each test slide. Onset of a slide started a timer which recorded RTs to the nearest millisecond. Slide and timer were simultaneously terminated by $S$ 's response on a two-key response panel. A feedback display located to the left of the screen operated automatically to present a reward light when $S$ responded both correctly and quickly. To be rewarded, fourth-grade and college Ss were required to respond within $.85 \mathrm{sec}$, and kindergarten $\mathrm{Ss}$ had to respond within $1.05 \mathrm{sec}$. Slides were programmed to occur at a rate of one per $5 \mathrm{sec}$.

\section{PROCEDURE}

On Day 1 kindergarten and fourth-grade Ss were given simple RT training before the recognition task was explained. Each child was taught. first with the right hand and then with the left. to respond within 


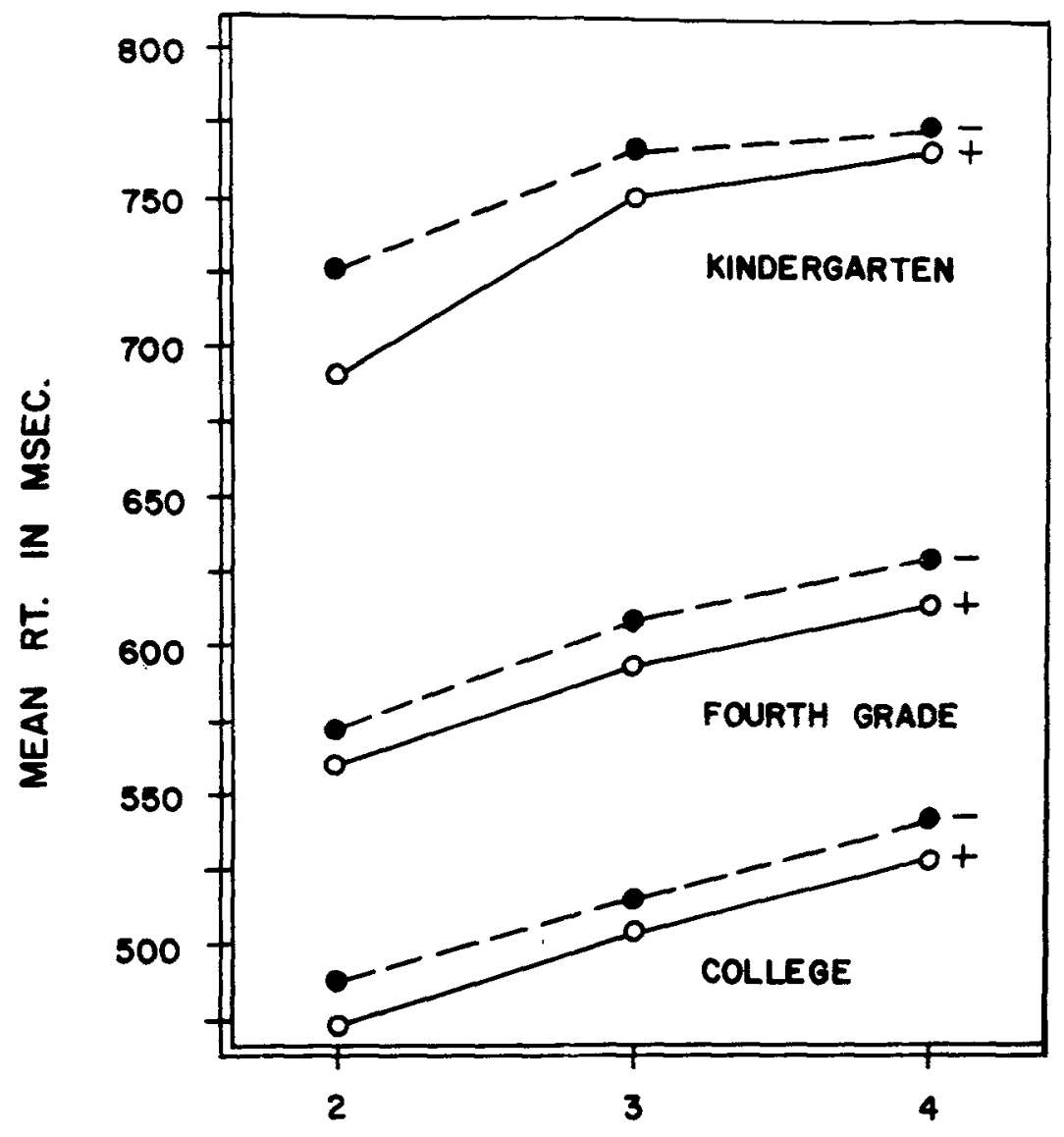

SET SIZE

$500 \mathrm{msec}$ to the onset of a slide. Two pictures which comprised the memory set in the practice task were then presented. The $S$ was instructed to press the right (positive) key when either picture appeared on the screen and to press the left (negative) key to any other picture. Usually only six to eight trials were necessary to insure that $S$ understood the task. Operation of the feedback display was demonstrated, and $\mathbf{S}$ was encouraged to respond as quickly and accurately as possible to each picture. College Ss were read instructions in place of pretraining. All Ss then received a block of 26 practice trials with feedback. A practice block was also administered prior to testing on Day 2 . The test procedure was identical in each session. Prior to a block of test trials, $\mathrm{S}$ was shown printed drawings of the memory set stimuli and was instructed to remember them. The drawings were removed and $S$ was required to name each from memory; this procedure was continued until no errors occurred.

\section{RESULTS}

Error rates for kindergarten, fourth-grade, and college Ss were $12.1 \%$, $10.0 \%$, and $4.7 \%$, respectively. Each S's RT performance was summarized by six scores based on correct responses (whether rewarded or not) over the two days of practice. Mean RTs were computed for positive and negative trial types at Set Sizes 2,3 , and 4 . In an analysis of variance, significant main effects were obtained for grade level $(\mathrm{F}=74.49, \mathrm{df}=2 / 48, \mathrm{p}<.01)$, trial type $(F=5.92, \mathrm{df}=1 / 48, \mathrm{p}<.05)$, and set size $(F=32.00, d f=2 / 96$, $\mathrm{p}<.01)$. Sex was not significant $(F=3.63$, $\mathrm{df}=1 / 48, \mathrm{p}>.05)$, and no interactions among the four variables were significant. The results can be seen in Fig. 1, which presents data for each grade level separately. Younger Ss reacted more slowly than older Ss. Within each grade level, RTs were longer on negative than on positive trials. The mean differences between RTs on positive and negative trials were 18.2 , S.E. $=14.2 ; 16.3$, S.E. $=9.7$; and 11.9, S.E. $=6.3 \mathrm{msec}$ for kindergarten, fourth-grade, and college students, respectively. It can also be seen in Fig. 1 that RT increased directly with set size. The linear component of the set size variable was highly significant and accounted for $95.3 \%$ of the variance $(\mathrm{F}=47.75, \mathrm{df}=1 / 48, \mathrm{p}<.01)$ attributable
Fig. 1. Mean correct RT as a function of set size. The data are plotted separately for positive (+) and negative $(-)$ responses within each grade level.

to set size: the quadratic component was insignificant $(F=3.03 . \mathrm{df}=1 / 48 . \mathrm{p}>.05)$. Figure 1 shows that the slopes of the $\mathrm{RT}$ /set-size functions are remarkably uniform across the three grade levels and the two trial types. Neither the linear nor the quadratic component of set size interacted significantly with grade level or trial type.

Data from positive and negative trials were combined to obtain for each age group an estimate of the rate at which items in memory are scanned. Slopes of the resulting functions indicate search rates per item of 30.1 , S.E. $=8.6 ; 30.1$, S.E. $=6.9$; and 26.7, S.E $=5.5 \mathrm{msec}$ for kindergarten, fourth-grade, and college $S s$, respectively. Mean RTs averaged across set size were $746 \mathrm{msec}, 595 \mathrm{msec}$. and $508 \mathrm{msec}$ for kindergarten, fourth-grade, and college Ss. DISCUSSION

The striking result of the present study is that the slope of the RT function was not significantly different across age. Differences between the RTs of children and adults were found to exist completely in intercept differences. Within the theory of recognition memory proposed by Sternberg, the longer RTs of children may be attributed to slower perceptual and motor processes, but not to slower memory search. It is surprising that young children are so similar to adults with respect to the rate at which they scan memory. The data are, however, in agreement with those of Bracey (1969), who also observed parallel linear functions for fourth-grade and college Ss. Both the data of Bracey and that of the present investigation are consistent with the view that children as well as adults amploy a serial exhaustive memory search in a recognition reaction-time task. The present findings indicate that the memory search involved in picture recognition is relatively primary and can be executed efficiently by young children.

\section{REFERENCES}

BRACEY, G. W. Stimulus encoding and high speed memory scanning in children and adults. Paper presented at the biennial meeting of the Society for Research in Child Development, Santa Monica, California, March 1969.

STERNBERG, S. Retrieval from recent memory: Some reaction-time experiments and a search theory. Paper read at Fourth Annual Meeting of the Psychonomic Society, 1963.

STERNBERG, $S$. High speed scanning in human memory. Science, 1966, 153, 652-654.

STERNBERG, $S$. Two operations in character recognition: Some evidence from reaction-time measurements. Perception \& Psychophysics, 1967, 2, 45-53. 